\title{
Erratum: Editorial: Measuring social impact investment
}

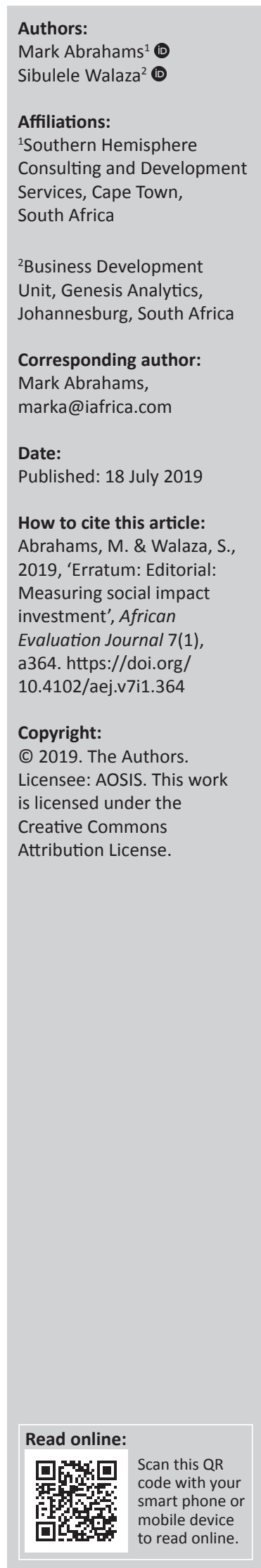

In the version of this article published earlier, the name of the second author, Sibulele Walaza, was unintentionally misspelt as Sibongile Walaza. The second author's name, affiliation and ORCID are hereby updated to Sibulele Walaza, Business Development Unit, Genesis Analytics, South Africa, ORC ID: https:/ / orcid.org/0000-0002-5859-2139.

In addition, the following acknowledgement statement was omitted from the article published earlier. The statement is hereby updated and added: 'Genesis Analytics and Sibulele Walaza, the guest editor for this edition, coordinated a call for papers and called on the support of several individuals to assist the authors in preparing their papers. The following individuals assisted the authors of the Social Impact Investment papers: Zenda Ofir, Jane Reisman, Nicole Mertens, Yaquta Fatehi and Bianca Samson. We are grateful for their contribution'.

This correction does not alter the significance or overall interpretation of the editorial. The editor apologises for any inconvenience caused. 


\section{Editorial: Measuring social impact investment}

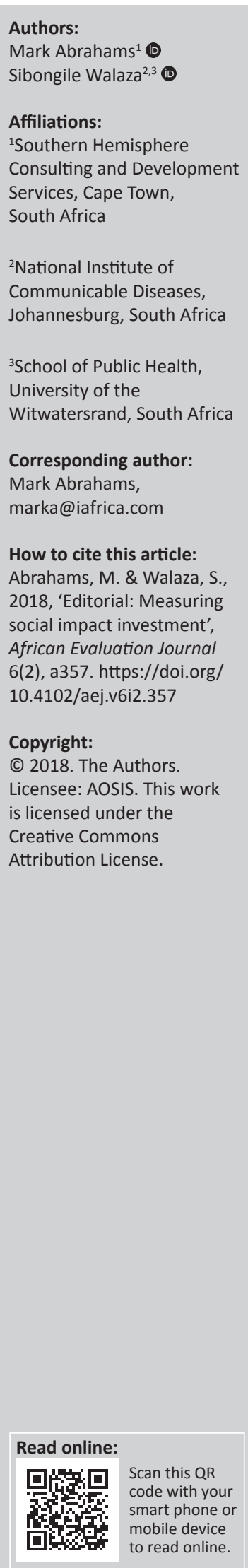

An interesting focus of this edition of the African Evaluation Journal is social impact investment. We have a particular interest in how to measure its success or its impact. Social impact investment was made a prominent strand at the American Evaluation Association conference in 2017 and it served almost as a parallel conference focus during the event. According to reports, social impact investing was introduced in 2007 to mobilise much needed capital to fund societal problems. Global awareness of the approach was increased through reports generated by the Rockefeller Foundation in 2010 and the World Economic Forum in 2011. At the core of social impact investment is the desire to bring about social impact while at the same time generating a financial return on investment. The rise of social impact investing is explained as follows:

- A response to the scale of social and environmental problems facing the world today and how this is beyond the scope of any government budget.

- The fact that more capital needs to be directed toward tackling social and environmental problems.

- New business models are demonstrating it is possible (and increasingly profitable) to achieve financial and social/environmental returns.

- Investors are increasingly interested in divesting from fossil fuels and other socially/ environmentally detrimental businesses and industries. They are also investing in firms and organisations that are 'doing good'.

- That generational change is occurring in the philanthropic sector, where millennials heading family funds are bringing a different value set and approach (Logue 2017:1).

For this edition, we were supported by the Rockefeller Foundation to explore the topic and authors who were immersed in the topic were encouraged to contribute. We specifically asked for two 'Invited papers', not peer-reviewed, for this edition. The first invited paper, 'The next frontier for measurement and evaluation: Social impact measurement for impact investing and market solutions', written by Hoffman and Olazabal (2018), posits that innovative finance, impact investing and market solutions are expanding the pool of capital available for social and environmental good. They state that market-based solutions such as impact investing require evaluators to further evolve their toolkits to meet the needs of a broader and more differentiated and fragmented client base. They maintain that conventional evaluation frameworks, theories, tools and approaches are foundational, but ultimately fall short of impact investors' needs for cost-effective, timely data and evidence about social and environmental returns. The second invited paper, 'Measuring our investment in the future', by De Witt (2018), draws on the work of the Bertha Foundation, who believes that innovative finance is an approach to funding enterprises and interventions that optimises positive social, environmental and financial impact. She states that the impact measurement community is starting to reorganise their roles as these evolve from being evaluation specialists to leading the charge in finding value in investment. According to her, evaluators are starting to work out how much extra value is actually being created by using certain business models. These two introductory articles provide a useful launch point for engaging with the other articles included in this edition.

Choda and Teladia (2018) share 'conversations about measurement and evaluation in impact investing' using the interactions emanating from the management of the 'Innovations in Evaluation' strand at the African Evaluation Association Conference, convened in Uganda in March 2017. Part of the conversation reveals that the conceptual definition of 'impact' differs between stakeholder groups. Impact measurement is generally concerned with collecting, analysing and communicating the environmental and social impact of an impact investment. For instance, for some stakeholders impact is the direct change that has occurred, basically the product of the outputs. They conclude that impact investing, defined as investments made into companies, organisations and funds with the intention to generate social and environmental impact alongside a financial return, is an emerging field that has grown rapidly in the last few years, outside international development. 
Barnett et al. (2018) present three lessons from Ghana to illustrate an understanding and optimisation of social impact of venture capital. According to them, the research demonstrated the usefulness of a theory-based approach but found it helpful to develop a smaller set of typologies to capture different impact pathways - a more efficient way to assess and report on social returns. Other lessons include the value of rural businesses and the potential to further extend impacts to lower income groups. They conclude that further research is needed on two fronts. Firstly, research is needed into the scale of the small and medium enterprises (SMEs) and the associated investment required. Secondly, further field-testing of different evaluation techniques is needed to help stakeholders better understand and improve the social benefits of venture capital.

Verrinder et al. (2018) discuss evaluative tools in impact investing by focusing on the benefits of using the theory of change approach. They state that the evaluation community has many tools that could be adapted and used in the world of impact investing. Their article explores the development and use of theories of change as a tool for impact investing and seeks to identify the benefits of the tool. According to them, the theory of change is used to identify and test causal mechanisms of an investment and the assumptions made in the path from activities to desired impacts. It must include (usually depicted graphically) the underlying logic, assumptions, influences, causal linkages and expected outcomes of a development programme. Three case studies are presented and the article aptly concludes:

However, theories of change alone do not provide a panacea to the impact challenge and also come with trials in their implementation. Specifically, the need to rigorously measure impact is not fulfilled by merely identifying what needs to be measured, how it will be measured and by whom. Measurement requires its own investment, resources, commitment and research. (Verrinder et al. 2018:8)

We are grateful to the Rockefeller Foundation for its support to explore this topic in this way and trust that this theme will be picked up in future editions.

Lubinga et al. (2018) assessed the impact of a statutory levy expenditure in four industries (citrus, deciduous fruits, table grapes and wine) in South Africa on the social welfare of these communities. The article suggests that 1 rand spent on export promotion and market development (EPMD) for the four industries in question, on average, generates \$26 worth of improvement in social welfare. The statutory levy expenditure on EPMD therefore played a key role in enhancing social welfare improvement. The authors argue for a need to mobilise more resources to facilitate the EPMD initiative into new markets and products for the industries. Kagoya and Kubuule (2018) discuss the quality assurance of the health management information system in Kayunga district, Uganda. At the time, the systems were manual and paper-based. Less than $25 \%$ of health centres (HCs) practised quality assurance measures during collection, compilation, analysis and dissemination of Health Management Information System (HMIS) data. Human resource challenges included understaffing where $43 \%$ of participating HCs did not have designated HMIS staff. They concluded that training and support supervision of HMIS focal persons was required to strengthen quality assurance of HMIS. The implementation of electronic HMIS dashboards with data quality checks should be integrated alongside the manual system.

Finally, Cloete (2018) presents his insights of policy indicator consistency and coherence in measuring public sector development programmes in South Africa. Cloete asserts that the South African government has over time developed separate policy indicator frameworks to measure governmental programme performances. Among these are a series of national development indicators to measure longterm societal transformation impacts and medium-term strategic framework indicators to measure the implementation of the National Development Plan. Then there are indicators to measure progress towards achieving the government's 14 strategic programme outcomes and a separate set of environmental indicators. Cloete doubts the efficiency of management efforts regarding implementation.. He argues for improved consistency, coherence, balanced and integrated measurement of sustainable development outcomes and impacts for South Africa.

\section{References}

Barnett, F., Jackson, E., O'Flynn, P., Ismaila, H. \& Agyeyomah, C., 2018, 'Understanding and optimising the social impact of venture capital: Three lessons from Ghana', African Evaluation Journal 6(2), a335. https://doi.org/10.4102/aej.v6i2.335

Choda, A. \& Teladia, M., 2018, 'Conversations about measurement and evaluation in impact investing', African Evaluation Journal 6(2), a332. https://doi.org/10.4102/ aej.v6i2.332

Cloete, F., 2018, 'Policy indicator consistency and coherence in measuring public sector development programmes in South Africa', African Evaluation Journal 6(2), a338. https://doi.org/10.4102/aej.v6i2.338

De Witt, S., 2018, 'Measuring our investment in the future', African Evaluation Journa 6(2), a343. https://doi.org/10.4102/aej.v6i2.343

Hoffman, S.A. \& Olazabal, V.M., 2018, 'The next frontier for measurement and evaluation: Social impact measurement for impact investing and market solutions', African Evaluation Journal 6(2), a342. https://doi.org/10.4102/aej. v6i2.342

Kagoya, H.R. \& Kibuule, D., 2018, 'Quality assurance of health management information system in Kayunga district, Uganda', African Evaluation Journal 6(2) a238. https://doi.org/10.4102/aej.v6i2.238

Logue, D., 2017, 'Explainer: The rise of social impact investing', The Conversation, 31 March, viewed 23 October 2018, from https://theconversation.com/explainerthe-rise-of-social-impact-investing-73357

Lubinga, M.H., Mazibuko, N., Ngqangweni, S., Potelwa, Y.X. \& Nyhodo, B., 2018, 'Impact of export promotion and market development on social welfare in South Africa: Evidence from the agricultural sector', African Evaluation Journal 6(2), a245. https://doi.org/10.4102/aej.v6i2.245

Verrinder, N.B., Zwane, K., Nixon, D. \& Vaca, S., 2018, 'Evaluative tools in impact investing: Three case studies on the use of theories of change', African Evaluation Journal 6(2), a340. https://doi.org/10.4102/aej.v6i2.340 